\title{
Self-Knowledge and the Science of the Soul in Buridan's Quaestiones De Anima
}

\author{
Susan Brower-Toland, Saint Louis University
}

Buridan holds that the proper subject of psychology (i.e., the science undertaken in Aristotle's De Anima) is the soul, its powers, and characteristic functions. Accordingly, at the outset of (the final version) of his Quaestiones De Anima $(Q D A)$ he argues that this science should not be understood as including the body nor even the soul-body composite as its proper subject. ${ }^{1}$ Rather, on his view, the subject of psychology is just "the soul in itself and its powers and functions insofar as they stand on the side of the soul" ( $Q D A \mathrm{I}, \mathrm{q}$. $1)^{2}$

Buridan takes it as obvious that, even thus narrowly construed, such a science is nonetheless possible. Thus, citing the authority of Aristotle, he claims that even if "the soul is inseparable from the body and could not function without the body, it is still possible to study the soul in itself by studying the attributes and predicates that are suited to the soul in itself" (QDA I, q. 1). To the extent that the science of psychology includes the human or intellective soul, however, Buridan's claim regarding its possibility is far from obvious. After all, like most of his contemporaries, Buridan takes the human soul to be immaterial. He readily admits, therefore, that "the intellect cannot be sensed". Nor are the intellect's acts or operations accessible to the senses. And yet, on

* I'm grateful to Jeffrey Brower for comments on an earlier draft of this paper.

${ }^{1}$ As Buridan lectured on De Anima multiple times, his commentary on this work exists in several versions. I rely mainly on his third and most mature redaction. References to and English quotations of this work are from the forthcoming critical edition and translation (hereafter, QDA). (In some cases, however, I have slightly-and silently-modified the English translation.) I will have occasion, in what follows, to consider two other, earlier versions of Buridan's lectures on De Anima, namely, (1) an earlier redaction, labeled in some of the manuscripts as the non de ultima lectura (= QDANV) and (2) a $16^{\text {th }}$ century edition made by George Lokert (= QDA). Both of these earlier versions are collected and edited by Patar. See Buridan (1991). For a helpful summary of the various De Anima commentaries attributed to Buridan as well as careful assessment of the veracity of their attribution to Buridan see Bakker and de Boer (2011).

${ }^{2}$ A detailed treatment of Buridan's account of the nature and proper subject of the science of psychology can be found in Zupko (2003, ch. 13). For a discussion of epistemic issues surrounding Buridan's account of scientific knowledge in general see Klima (2009, ch. 11). 
Buridan's broadly empiricist theory of knowledge, all (human) knowledge, including knowledge of the intellect or intellective soul ${ }^{3}$, takes its start in the senses and in what can be derived from the senses. How, then, is a science of the human soul possible? In particular, what is the nature or source of our knowledge of the intellect?

Given the centrality of such questions to the enterprise of the De Anima itself, we might naturally expect Buridan's commentary on this work to include a systematic consideration of them. Surprisingly, however, it does not. The closest Buridan comes to addressing such issues is a single question in Book III of QDA, where he considers "whether the intellect can intellectively cognize itself'. Buridan's response to this question consists in an account of how-despite its inaccessibility to the senses - we come posses a concept of the (immaterial) human intellect. Even here, however, crucial details of the account are left obscure. Buridan seems to think, for example, that our general concept of the intellect is grounded in a kind of self-directed awareness. In particular, he argues that that our concept of intellect is inferentially derived from "experience" of our own intellective states and rational activities. Yet, he is utterly silent on questions about the nature of our access to such states and activities. Much in what follows, therefore, is an attempt to reconstruct some of the key, but undeveloped, elements of Buridan's account.

My discussion divides roughly into two parts. In Section 1, set out the main elements of Buridan's account of how we come to cognize the intellect. I begin by summarizing what he says about the genesis of our concept of the intellect (in 1.A); I then consider his account of our cognition of our own intellective states (1.B). As the discussion in Section 1 will make clear, Buridan holds that our concepts of intellect and of intellective states are both derived (inferentially) from subjective "experience" of our own states and rational activities. In Section 2, therefore, I try to elucidate Buridan's notion of experience. Ultimately, I argue that it is a non-conceptual, non-discursive mode of self-awareness. I suggest, moreover, that it might best be understood

\footnotetext{
${ }^{3}$ Here and in what follows, I move freely between speaking of the 'intellect', the 'intellective soul', and the 'soul'. Buridan holds that there is but one soul in human beings (hence, no ontological distinction to be drawn between the vegetative, sensitive, and intellective soul). See $Q D A$ II, q. 4; and III, q. 17. Buridan also denies that the (principle) powers of the soul are distinct from the soul itself (II, q. 5). Thus, on his view, 'intellect' refers to the human soul just insofar as it is the principle or power for rational thought. For more on Buridan on the unicity of soul, see Lagerlund (2004) and de Boer's contribution to this volume.
} 
in terms of our own notion of phenomenal consciousness. On the interpretation I advance, then, it turns out that, for Buridan, our concept of the intellect itself and, hence, the science of (human) psychology in general, is ultimately grounded in phenomenal experience of our own intellective states.

\section{How Does the Intellect Cognize Itself and Its States?}

Before turning specifically to Buridan's treatment of how we cognize the intellect, it will be useful to begin with a word or two about his views regarding cognition in general. Following Aristotle, Buridan holds that all cognition begins from and depends on sensory cognition. In particular, cognition takes its start when various sensory impressions, which Buridan refers to as "sensible species", are received in external sensory organs. These impressions or species are then transmitted an internal sense organ - which Buridan refers to variously as the "common sense" or "cogitative power" and collated by it in various ways. This faculty of internal sense serves, likewise, as the center for (sensory) memory and imagination. ${ }^{4}$

Intellective cognition (which includes cognitive operations such as concept formation, judgment, and discursive reasoning) takes its start from the sensory representations (or 'phantasms') supplied to intellect by the internal sense. Indeed, on Buridan's view, the first and most fundamental acts of intellective cognition-namely, acts of forming (singular and universal) concepts - are themselves just intellective operations on sensory contents. ${ }^{5}$ Inasmuch as the raw data provided by the external and internal senses is a prerequisite for formation of intellective representations or concepts (i.e., "intelligible species") Buridan holds that all intellective cognition is ultimately grounded in and derived from sense experience. In this, his views are typical of those held by medieval Aristotelians.

Against the backdrop of this broadly empiricist approach to concept acquisition, questions about the nature of our cognitive access to immaterial realities such as the rational soul are especially pressing. Buridan himself

\footnotetext{
${ }^{4}$ Buridan's account of sense cognition is developed in Book II of his $Q D A$. An overview of Buridan's account of sense cognition can be found in Sobol (2001). See also Sobol's chapter in the present volume.

${ }^{5}$ In fact, Buridan is inclined to identify the intelligible species with phantasms-namely, with acts of the cogitative power. See $Q D A$ III, q. 15. A detailed treatment of Buridan's account of intelligible species especially in connection with his views about cognition of universals can be found in Zupko (2013).
} 
explicitly acknowledges the bearing of such questions on prospects for a science of the soul. As he explains at the outset of his $Q D A$ :

[T] he science of the soul is the most difficult for us, and consequently the most uncertain... This is because our intellect [which is immaterial] cannot be sensed, and yet, owing to the weakness of our intellect, we for our part can comprehend only what can be sensed or deduced from what can be sensed, as mentioned earlier. ... [T]o the extent that the soul can think about something only by means of the senses, it is to that extent more difficult for it to be able to grasp itself. (I, q. 4)

While acknowledging the "difficulty" of arriving at knowledge of the soul, Buridan assumes, nevertheless, that scientific (i.e. demonstrative) knowledge of the soul is attainable. Surprisingly, however, he devotes relatively little attention to questions surrounding the nature of our cognitive access to an immaterial intellect. There is, as I alluded earlier, just a single question in the entire $Q D A$ that bears directly on this issue-namely, III, q. 9.

The question Buridan addresses at III, q. 9 is this: "Can the human intellect intellectively cognize itself?" 6 Although the wording might suggest otherwise, the question is not principally concerned with the issue of selfknowledge. ${ }^{7}$ That is to say, the issue at stake is not so much focused on whether we can reflexively cognize our own individual intellect, but rather on whether-or rather, how-we come to possess a concept of intellect in general. Interestingly, however, it turns out that our generic concept of intellect presupposes, indeed owes to, our awareness of our own intellect and intellective states. Thus, while III, q. 9 is not, as I say, principally a question about self-knowledge, Buridan's response to it does in fact presuppose our being reflexively aware of our own intellective states. To see this, we need to look more closely at the text itself.

\footnotetext{
${ }^{6}$ This question about whether the intellect can cognize itself is taken up in all of the various redactions of Buridan's De Anima commentary. Although my discussion focuses primarily on Buridan's third and, hence, most mature treatment of this question, I'll occasionally consider his treatment of the issue in earlier redactions. The basic line of argumentation is the same, however, in all three versions.

${ }^{7}$ In referring to intellect's knowledge of itself as "self-knowledge", I do not mean to commit myself to the view that Buridan identifies the human person (i.e., that to which the first person pronoun refers) exclusively with the soul rather than the soul-body composite. Even if this is in fact Buridan's view (see, e.g., Lagulund, op. cit.) nothing in my discussion turns on this and so I mean to remain neutral on such matters.
} 


\section{A. How does the Intellect Cognize itself?}

Although Buridan's response to this question about whether intellect cognizes itself begins with a battery of arguments in support of a negative reply, it is clear that there is, in fact, no real controversy on the matter. "Everyone," Buridan reports, "grants...that the human intellect can intellectively cognize itself." Indeed, as he points out, much of the enterprise undertaken in the De Anima itself presupposes the intellect's intelligibility to itself. ${ }^{8}$ Were this not the case there would be little point in the attempt to develop a science of the human soul. The real question at issue, then, is not whether we can cognize the intellect but rather how we do so. It is, then, this latter question that Buridan sets out to answer in III, q. 9.

Buridan holds that, in at least one sense, cognition of the intellect is "easy" and unproblematic. In fact, he is willing to allow that so long as we possess any concept that includes the intellect in its extension we can be said to understand or intellectively cognize (intellegere) the intellect. Thus, he writes:

rustics and market women easily understand the intellect itself, because they can easily form common concepts from which the names 'being', 'thing', 'one', 'something', etc., and others similar to them, are taken. (QDA III, q. 9)

Of course, this is rather too easy. While it's obviously true that concepts such as 'being', 'one', 'substance', and 'form' include the intellective soul in their extension, they include much else besides. And inasmuch as these concepts apply equally to things vastly different from the intellect, their possession hardly counts as cognition of the intellect. Indeed, it's hard to see that possession of such concepts yields knowledge of the intellect itself. In any case, since we obviously do have concepts that apply uniquely to the intellect, the more interesting and important question is: how do we arrive at a concept specific to the intellect?

In answering this latter question Buridan begins by ruling out what, in his day, would have represented a broadly Augustinian answer to this questionnamely, that the intellect is somehow just directly acquainted with itself. On the Augustinian view, as Buridan describes it here, the intellect simply "knows itself through its own essence", that is, knows itself immediately

\footnotetext{
${ }^{8} \mathrm{He}$ writes "...this is apparent since we do come to knowledge of the intellect, which would not happen if the intellect did not intellectively cognize itself” (QDAL III, q. 9).
} 
without recourse to any discursive or representational processes. ${ }^{9}$ On Buridan's view, however, such a position is patently false:

The human intellect does not intellectively cognize itself through its essence - that is, without needing anything else that is representative, because then it would always intellectively cognize itself. And it would intellectively cognize itself in the highest degree non-discursively, and [cognize] nothing prior to [cognizing] itself-much like the divine intellect. But experience shows this to be false, and it is contrary to the determination of Aristotle. (QDA III, q. 9)

As Buridan sees it, if intellect's access to itself were direct in this way, the intellect would (i) cognize itself at all times and (ii) cognize itself prior to and independently of its cognition of other all other things. But, on his view, these entailments violate both common sense and the authority of Aristotle. As Buridan sees it, we know from experience that we are not always aware of our intellect. Likewise, he thinks, experience confirms the Aristotelian dictum that "the intellect itself is not sufficient for intellective cognition of itself or of anything else without the sense." As he explains more fully:

In order to intellectively cognize we experience that we need an act of sensing with respect to exterior or interior sense, which is why we do not intellectively cognize anything in a perfectly dreamless sleep. And it is in just this way that we need [an act of] sense-namely, to represent intelligible things to [the intellect] by means of species of them. Initially, however, senses represent only sensible things to intellect, and what is first represented to it is what it first understands. Hence, it intellectively cognizes what is sensible before it intellectively cognizes what is not sensible; but it is itself not sensible on account of its immateriality and indivisibility. Therefore, it intellectively cognizes what is other than itself before it cognizes itself ( $Q D A$ III, q. 9)

In this passage, Buridan is merely following the standard Aristotelian line that intellect always depends for its act on information present in sensory representations - namely, sensible species and phantasms - on the basis of

\footnotetext{
${ }^{9}$ It was common among medieval philosophers to represent Augustine's contention that "the mind knows itself through itself (per seipsam)" as the claim that the mind or intellect knows itself immediately and through its own essence (per suam essentiam) rather than by recourse to any inferential or representational processes. And this is because, on the Augustinian picture, intellect is somehow immediately acquainted with itself. As Augustine himself famously remarks: "what is more present to the mind than the mind itself?" (De Trinitate 10.16)
} 
which it is capable of forming (or receiving) acts representative of the universal nature of the items present to it via senses. ${ }^{10}$ Hence, knowledge of the intellect-like all other forms of knowledge-depends on information present to the senses.

However, as we've noted already, the intellective soul is immaterial and, hence, not accessible to the senses. We cannot, therefore, form a concept or representation proper to the human intellect merely from information present in sensible species and phantasms. Nor is such a concept innate: hence, Buridan insists, a concept or species representing intellect cannot be "produced immediately in [the intellect] itself". ${ }^{11}$ The only remaining alternative is that such a concept must be derived via discursive reasoning. "That you can do this [viz., form a concept proper to intellect] discursively is obvious," Buridan explains, since

you experience that you cognize universally and that you learn universal conclusions by syllogizing. But you judge that this could not occur without a cognitive power (potentia cognoscitiva). Therefore, you conclude that there is, in humans, a discursive power that cognizes universals. ( $Q D A$ III, q. 9)

As this passage suggests, Buridan thinks that we arrive at a generic concept of the intellect via reflection on our experience of our own intellective states and rational activities. We can, for example, move from awareness of our possessing universal concepts and of our ability to engage in reasoning involving such concepts to the conclusion that there exists in us a rational faculty that grounds our capacity for such concepts and conceptual activities. $^{12}$ And this faculty or power just is the human intellect (which, incidentally, Buridan identifies with the soul itself).

\footnotetext{
${ }^{10}$ For a fuller treatment of Buridan's account of concept formation see: Klima (2004); King (2001).

${ }^{11}$ QDANV III, q. 10 “...for if it did this it could always produce that species [in itself immediately] and it would. But, in that case, it would always intellectively cognize itselfwhich is false."

${ }^{12}$ See also QDANV III, q. 10 where Buridan elaborates on the kinds of intellective states that
serve as the basis for inferentially derived concepts of the intellect. In this context, he also
gestures at reasons for including 'incorporeal' in this concept. Thus he writes: "From these
things it follows that intellect understands itself through a discursive process from other
things previously grasped by the intellect. [...] For example, we experience that we cognize a
thing universally, that we infer to future things from things that happened in the past, and that
we have doubts about the causes of sensible things (causes that are not sensed by us). We
} 
The concept formed in this way is, clearly, a concept that is proper to the intellect - that is to say, one that refers to all and only human intellects. But this concept will likewise be descriptive. In the case Buridan describes above, for example, the concept of the intellect is on that is derived from an awareness of oneself as possessing concepts that are universal in content (and as using such concepts in discursive/deliberative processes). In that case, then, the concept of the intellect is merely the concept of 'a power in human beings to recognize universals' or 'a power in human beings to engage in discursive thought'. Interestingly, however, Buridan goes on to say that, in addition to this, we also can form a simple (i.e. semantically unstructured and, so, directly referential) concept of intellect. And this is because, on his view,

the intellect by its very nature is suited to elicit and form a simple and absolute concept from concepts of extrinsic accidents. ... While it seems to many that we cannot have such simple substance concepts, because no one having such a concept can describe it to one who does not have it in a way that leads to his having it-unless by a description based on accidents of things known to that person. But we will say that from this description, his intellect is naturally suited to elicit a similar substance-concept... ( $Q D A$ III, q. 9)

In other words, Buridan thinks the intellect possesses an innate capacity to form simple substance-concepts (such as the concept 'intellect') from complex descriptive contents involving accidental or extrinsic features of the substance in question. Thus, once one possesses descriptive knowledge of the nature of the intellect, one can go on to elicit (or immediately form) a further concept - one that is both simple and proper to the intellect.

This, then, is Buridan's account of how intellective cognition of the intellect itself occurs. To be sure, a full-fledged science of the human soul requires further inquiry into questions about the precise nature the human intellect, its operations, and its relation to the body. ${ }^{13}$ Yet, insofar as such inquiry

infer that all these cognitions do not pertain to a corporeal, extended sensory power. Quite the contrary: we experience that we have reasons for actions which conflict with sense-based cognitions [species] and appetites. Therefore, we conclude that there is in us some other cognitive power... and we call such power the 'human intellect'."

${ }^{13}$ E.g., with regard to the intellect itself, Buridan goes on to consider questions about whether it is active or passive; whether it is immaterial; whether there is only one or whether there as many intellects as human beings. In connection with his investigation of the intellect's operation he considers, for example, whether that operation require intelligible species, and whether it grasp what is universal before what is singular is or vice versa. 
presupposes our possession of a basic concept of intellect and its characteristic activities, Buridan's account of how we form such a concept supplies the necessary groundwork for a science of the soul. It is by now clear, moreover, that, for Buridan, this science is ultimately founded on a kind of self-knowledge. For, as we've now seen, he holds that our concept of the intellect is derived from subjective awareness of and reflection on our own intellective states and activities. In this sense, therefore, his account presupposes that we possess some kind of reflexive-awareness our own occurrent states. ${ }^{14}$ In fact, Buridan holds that it is just in virtue of this capacity for introspective reflection that the intellective soul may be uniquely characterized as a "reflexive power." 15

Of course, these observations do little more than push our original question back a step from a question about the nature of our access to the intellect to

Finally, in connection with its relation to the body he considers whether it is the substantial form of the body, whether it inheres in the body, and whether it inheres in the body as a form distinct from the sensitive soul?

${ }^{14}$ It may be, moreover, that his account also presupposes that we likewise possess (perhaps implicitly) a kind of reflexive-awareness of our own intellect. After all, on his view the discursive process that yields a general concept of intellect includes, as an intermediary step, recognition that there exists "in oneself" a power or capacity for universal thought, syllogistic reasoning, etc. As he describes it, the discursive process is one in which we first "conclude that there is in us some ...cognitive power... and we call such power the "human intellect"”.

${ }^{15}$ Buridan appears somewhat ambivalent regarding the precise characterization of a so-called reflexive power. While reflexivity is traditionally associated with the intellect just insofar as it is both immaterial and capable of reflecting on itself, Buridan associates reflexivity with the capacity for discursive or inferential cognitive processing. So understood, he sees no obvious conceptual connection between reflexivity and immateriality. Thus, in QDAN III.3, in the context of discussing Alexander's arguments for materialism about the intellect, Buridan allows that one might legitimately argue that the capacity for discursive thought (and, hence, for reflexivity) belongs properly to material substances. In his earlier De Anima commentary, however, he suggests that it is the capacity for introspective, or self-directed discursive thought that ultimately distinguishes the intellect (from the senses) as a reflexive power. He writes: "It is customary to say that a sense does not sense itself, and that this is so give that an extended body is not reflexive on itself; but these ways of speaking are obscure. For it is not clear to me what we ought to understand by the intellect's being reflexive on itself unless by this we have in mind a discursive process by which the intellect reasons discursively from things previously understood to an intellectively cognition of itself (and of other things not accessible to the senses). Taken in this way, we can say that sense does not sense itself-though perhaps an interior sense is in some way a discursive power when it comes to things are necessary for [its] life. Even so, it is not sufficiently discursive for comprehending itself and other interior things.” QDANV III, q. 11. 
one about access to our intellective states. After all, the intellect's states and activities are no more available to sense perception than the intellect itself. How is it, then, that we cognize those intellective states from which we derive our concept of intellect itself? It is to this question that I now turn.

\section{B. How does the Intellect Cognize its States?}

To my knowledge, Buridan does not offer any account of the nature or means of the intellective soul's self-reflexive access to its own states and operations. In any case, his discussion at QDA III.9 does not address this question, nor does he take the issue up elsewhere in his Questiones De Anima. ${ }^{16}$ It's reasonable to suppose, however, that the same general considerations that inform Buridan's account of intellective cognition of intellect will apply equally in the case of its cognition of its states. We can get a sense for precisely the sort of position these considerations yield if we look to a related question in the anonymous De Anima commentary edited by Benoit Patar. ${ }^{17}$ Although, as now seems likely, this commentary is not rightly attributed to Buridan (as Patar supposes), I believe the discussion of state-reflexive cognition it contains, does help to shed light on Buridan's views. This is because the author of Patar's text, in shaping his account of how we cognize our intellective states, is motivated by very same principles that guide Buridan's account of how we cognize the intellect itself. It's not unreasonable to suppose, therefore, that the account we find in Patar's anonymous author (whom I shall henceforth refer to as 'Patar's anonymous' - or 'PA' for short) approximates something like Buridan's own account of how we intellectively cognize our own intellective states.

At question 11 of Book III of Patar's text, PA considers whether all acts of cognition are self-reflexive in nature. In particular, PA asks: "is every act of cognition a cognition of itself". Of course, an affirmative answer would yield a straightforward account of how we come to be aware of our own states. If cognitive states were all self-representing, then reflexive cognition of such states would be entailed by their very occurrence. As it turns out, it is precisely this implication that leads PA to deny that acts of cognition are cognitions of themselves. For if they were, it would follow that we always cognize our states - something PA wants to deny. "Someone can," he claims,

\footnotetext{
${ }^{16}$ And this holds, so far as I know, for all versions of his commentary. Interestingly, however, he does explicitly consider questions about the nature of our access to our sensory states. See $Q D A$ II, q. 22; q. 25.

${ }^{17}$ QDAP. Patar attributes this text to Buridan, but this attribution has recently (and, to my mind, quite compellingly) been called into doubt. See note 1 above.
} 
"see a stone and not actually cognize that he's seeing a stone" (QDAP III, q. 11). Of course, if this is right, then it is not the case that all acts of cognition are self-representing. Indeed PA goes on to suggest that knowledge of a given act of cognition must come by way of some numerically distinct, higherorder act - namely, one that represents the first-order act in question. ${ }^{18} \mathrm{PA}$ puts the point by calling attention to the following distinction:

These two spoken propositions differ: 'I intellectively cognize that a rock exists' and 'I intellectively cognize that I [intellectively] cognize that a rock exists' and likewise the mental propositions corresponding to them differ. And the second of the two is the cognition by which the first is determinately cognized. Therefore, no cognition is cognition of itself, but rather of something else. ( $Q D A P$ III, q. 11)

According to PA, therefore, whenever there is reflexive cognition of one's own intellective states this owes not to the occurrence of the state cognized, but rather to the occurrence of a numerically distinct, higher-order state. ${ }^{19}$

Of course, to explain intellective cognition of a given first-order state by appeal to the occurrence of higher-order representation of it is just to push the question back yet another a step. After all, how do we come to have the relevant higher-order cognition? If what we're looking for is an explanation of state-reflexive awareness, and the explanation we are given appeals to the presence of a higher-order act of cognition, then we then need some account of how we come to form the relevant higher-order state. As it turns out, PA offers us an explanation.

PA begins by pointing out intellective cognition of one's own acts clearly cannot arise via sense perception since such acts of cognition-like the intellect itself-are not accessible to the sense faculties. Here PA explicitly notes that the very same considerations that shape our account of how the intellect is cognized apply equally to the case of cognizing its states. He writes:

\footnotetext{
18 This follows only on the assumption that such knowledge comes by way of representations - an assumption which, I shall argue presently, Buridan rejects.

${ }^{19} \mathrm{PA}$ is willing to allow, however, (again echoing arguments Buridan make regarding cognition proper to the intellect) that a given act of cognition qualifies as self-representing in cases where its content represents or applies to cognitive states in general. As he explains: "I possess the following thought: "Every act of intellective cognition is in the soul'." But insofar as that thought applies to all acts of intellective cognition it applies to and, so, represents itself. But, again, this isn't a cognition proper to one's own intellective states.
} 
It must be noted, that the intellect, a species, an act of cognition, or habit... are all such that they cannot be cognized through any species proper to them. And this is because they are not things that can be sensed. (QDAP III, q. 11)

Given that it is not possible for the intellect to receive information about its own cognitive acts from the senses, it must, PA reasons, be the case that cognitive access to our intellective states comes by way of discursive processes. And here too, PA draws a comparison between how we cognize the intellect and how we cognize its states. As he explains, "the intellect, a species, and any other such thing is... not cognized by a species proper to it, but by means of discursive thought - and this is to cognize reflexively." 20 Thus, just as in the case of intellect, we form a higher-order concept or representation of our intellective states via some sort of discursive reasoning. Although the concept thus formed will be complex, or descriptive in nature, PA also allows that the intellect can go on to form a simple concept corresponding to it:

"We must note that sometimes the intellect, intellectively cognizing one thing not through a species proper to it, but through discursive reasoning afterwards places that thing before itself as a single cognized thing and further inquires about other conditions and categories concerning it. ( $Q D A P$ III, q. 11)

So far as it goes, the view articulated here represents what appears to be a faithful extension of the principles that inform Buridan's account of intellect's cognition of itself to the question of its cognition of its states. It's quite plausible to suppose, therefore, that Buridan's would endorse PA's conclusion that higher-order, state-reflexive representations can be formed only via discursive reasoning. Indeed, Buridan himself explicitly says as much at $Q D A$ III, q. 2 in the context of a discussion about whether intellect must, as Aristotle seemed to think, be devoid of what it cognizes. In reply, Buridan notes in passing that at least in the case of what intellect cognizes "discursively" it need not be devoid of what it cognizes. And this is clear, he claims, since intellect "cognizes itself in this way, and likewise cognizes the acts and dispositions inhering in it" but obviously isn't devoid of these things ( $Q D A$ III, q. 2). Evidently, therefore, Buridan holds much the same position

\footnotetext{
${ }^{20}$ For the same reason, any form of state-reflexive cognition is denied of non-rational animals since "the sensitive power of brutes is not a reflexive power" (QDAP III, q. 11).
} 
as PA: our cognition of the intellect and its states arises in the same way, namely, via some sort of discursive process. ${ }^{21}$

That said, it should be clear that this position is rather puzzling in light of our broader question regarding the grounding for the science of psychology. Recall where we began, namely, with a question about how we arrive at knowledge of the intellect given that (i) it is inaccessible to sense faculties and (ii) Buridan's commitment to a broadly empiricist account of concept acquisition. As we've now seen, Buridan holds that our concept of intellect is inferentially derived from awareness (experior) of our own intellective states and activities. But how do we come to be aware of our intellective acts and activities? So far all we've seen is the suggestion that (i) intellective cognition of our own intellective acts owes to our possession of higher-order representations of lower order states and (ii) such higher-order representations are, like our concept of intellect itself, discursively formed. But, then, how do we come form such higher-order representations? From what are they derived? Without an answer to these questions, Buridan's account of the source of our knowledge of the intellect remains fundamentally incomplete.

\section{Self-Knowledge and Self-Consciousness}

\footnotetext{
${ }^{21}$ One might wonder whether Buridan allows for the possibility that at least some token mental states can be singularly self-referential. After all, it is well-known that he explicitly acknowledges (and discusses at length various semantic paradoxes surrounding) selfreferential sentences in spoken and written language (see Buridan (1982, trans. Hughes). But it's less clear whether he would acknowledge the existence of singularly self-referential (token) thoughts. I know of no passage in which he explicitly considers such a thing. What is more, the fact that he denies material supposition in mental language might be taken as evidence against such a possibility. For Buridan on material supposition in mental language see Klima (2009, 29-32). Perhaps he would allow, however, that by using a mental demonstrative (i.e., whatever act or concept corresponds to the spoken term 'this') one could form a singularly self-referential thought (e.g., a mental sentence corresponding the written sentence 'this thought is false', or a concept corresponding to 'this concept'). Even were this the case, however, it would in no way undermine the conclusion of this section-namely, that, in general, acts of intellective cognition are not self-reflexive or singularly selfreferential. And the acts that Buridan says we "experience" and from which we derive our concept of intellect are not acts involving mental demonstratives. Hence, even if it turns out that mental demonstratives (or complex mental expressions involving them are selfreflexive) this has no significant bearing on the broader question regarding how we come to cognize our mental states in general.
} 
As the foregoing makes clear, the science of the soul (or at least that portion of the science which takes the human intellective soul as its subject) is, for Buridan, ultimately founded on a kind of self-knowledge. And this is because, he thinks that, our concept of intellect - a concept that serves as one of the fundamental principles for this science-is itself rooted in our subjective or "experiential" awareness of our own states and intellective activities. Interestingly, Buridan hints at the role such experience plays in the science of psychology at the very outset of his commentary on De Anima. For instance, at question 4 of Book I, in the context of discussing the difficulty and uncertainty of a science of the soul, Buridan argues that because we actually experience our psychological states, the science of psychology is more accessible and more certain than other sciences. After all, since knowledge of a substance comes by way of knowledge of its characteristic functions, it follows that we have more secure knowledge of those things whose function we are more familiar with. He writes:

many questions are easier for us, and able to be thought about with more certainty and demonstrated, if we have experience of the functions [involved], especially when compared to questions about many other forms whose proper functions we cannot experience in this way. ( $Q D A$ I, q. 4)

Hence, those substances whose functions we experience first-hand are more known to us. But, as he goes on to point out, "this is the case with functions of the soul, seeing that we experience them in ourselves". It's clear then, that Buridan assumes that self-knowledge - and, in particular, knowledge of our own cognitive activities and states-plays a foundational role in the science of the soul.

And yet Buridan's account of the nature and source of our knowledge of our intellective states and activities remains obscure. Although, as we've now seen, it is clear that he thinks we can form higher-order intellective representations of our states, it is likewise clear that these higher-order concepts - insofar as they are discursively derived from more basic concepts or experiences - are not themselves the ultimate source of our knowledge of our intellect or intellective states. Our original question about the nature of our access to the soul and its states remains, therefore, unanswered.

It is worth pointing out that, hitherto, I have been focusing exclusively on how we come to intellectively cognize-i.e., come to form concepts or intellectual representations of - the intellect and its states. This focus reflects Buridan's own concern to show that we can and do possess the concepts 
necessary to ground a full-fledged science of the soul. Even so, there is no reason to suppose that there are not other, more primitive forms of selfknowledge. In fact, it seems to me that Buridan's own account of how we cognize the intellect (and its states) presupposes the existence of some other, non-conceptual or non-representational access to the intellective soul and its states.

In order to see this, consider again Buridan's claim that our cognition of the intellect is discursive in nature: we infer our concept of intellect from our experience of our intellective states. It seems unlikely, however, that the mode of awareness that grounds this discursive process is itself discursive in nature-i.e. that the basis for our concept of intellect is itself a discursively formed concept (e.g., a higher-order representation of one or more first order states). Or, even allowing that it is, we might, nevertheless, expect that the latter concept must in its turn be grounded ultimately in some more direct, non-discursive awareness of one's states. After all, it's difficult to see how we could arrive in a discursive matter at some higher-order representation of an occurrent state of which we're altogether unaware. But, if this is right, then, Buridan's account of intellective cognition of both the intellect and its states presupposes some type of non-discursive, non-representational access to the intellective soul's first-order states.

While this line of reasoning is somewhat speculative, further support for it can be found in an interesting and somewhat puzzling argument Buridan makes in the course of developing his account of how the intellect cognizes itself. Thus, if we return to his discussion in $Q D A$ III, q. 9, we find Buridan making the following argument:

In another way, an old woman (vetula) intellectively cognizes her intellect since she experiences and judges that she knows and believes that no dog is a horse, and that every horse that she has seen is bigger than a dog. Therefore, she cognizes herself knowing and believing this. But since she cannot know these universal things except on account of her intellect, it follows that she, the one knowing and believing this, is not just a body but a composite of a body and an intellect. Therefore, by cognizing herself-i.e., a composite of body and intellect-knowing this, she cognizes both a body and an intellect - though she does so confusedly and not distinctly.

There's a lot going on here, but the overarching point, I take it, is just this: one can arrive at reflexive knowledge of one's intellective soul on the basis of some form of reflexive awareness of one's states. Of course, this claim is, 
by now, familiar enough. What's both interesting and puzzling about the passage is that while Buridan doesn't elaborate on the nature of the statereflexive awareness in question, what he does say certainly suggests that it is not to be explained in terms of one's possession of some higher-order concept or representation of one's states.

The evidence for this - such as it is - is two-fold. First, it's suggested by the language Buridan uses to characterize this mode of state-reflexive awareness, namely, as a matter of 'experiencing' one's states; second, it's suggested by the fact that this is a type of awareness characteristic of ordinary folk-the sorts of people Buridan refers to at various points in his discussion as "rustics" (vulgares) and "old women" (vetulae). I'll return in the next section to the possible significance of Buridan's use of the term 'experior'. But first, I want to focus on the remark about ordinary folk since what he says here strikes me as both significant and revealing. The upshot of the comment about the vetula in the foregoing passage is, I take it, to concede that even such as she-namely, someone unlikely to be engaged in philosophical reasoning and second-order reflection regarding the nature of her concepts and beliefs - even she can be said to possess knowledge of her intellect (though in a "confused" and general way). This knowledge, he claims, owes to her awareness or "experience" of herself as being in certain intellective states. As he says: "an old woman" who is aware of (i.e., "experiences") herself as having a certain belief (say, about dogs and horses) will "therefore, cognizes herself knowing and believing this". In other words, she will-via her awareness of a given belief - be aware of herself as its subject. And, Buridan continues, insofar as the subject of the belief is a composite of body and intellect, it follows that the woman, insofar as she is aware of herself as subject of her belief, is aware of or cognizes her intellect.

The significance of all this is, perhaps, by now clear. The sort of reflexive awareness the market woman has-namely, her "experience" of her intellective states - is, plausibly, neither discursive nor conceptual in nature nor inferentially grounded. That it's not inferential is, I believe, the very point of Buridan's characterizing it as (i) a kind of awareness characteristic of a "market woman" and (ii) yielding only a "confused", "indeterminate" knowledge of the intellect. And, of course, on Buridan's system, if it is not arrived at inferentially or discursively it is, for the same reason, also not conceptual (or representational) in nature. As we've seen, any concept or representation we have of our intellective soul or our cognitive states must arise out of discursive thought. Hence, the implication of the passage as a 
whole is that there exists a kind of direct, experiential, non-discursive, nonrepresentational access to our subjective states. ${ }^{22}$

One final point about the passage. It is striking that this reflexive awareness of one's states appears to involve a kind of reflexive awareness of one's own soul as well. That is, it appears that experience of one's states is such that it includes implicit awareness of oneself (or one's soul) as their subject. In any case, Buridan speaks (in the foregoing passage) as if the vetula's awareness or experience of her beliefs entails awareness or experience of herself. And in his way, his manner of speaking lends further support to the claim that he is committed to the intellect's possessing a distinctive mode of access to itself and its states - that is, access to itself via its experience of its states.

Now, if this line of interpretation is right, we can think of Buridan as distinguishing between two main types of intellective self-knowledge. On the one hand, there is what we might call 'subject-reflexive' self-knowledge. This is a type of knowledge or cognition the intellect possesses of itself as the subject of various acts or states. On the other hand, there is 'state-reflexive' self-knowledge where this refers to knowledge or cognition of those acts or states themselves. ${ }^{23}$ In addition to distinguishing these two types of selfknowledge, or reflexive cognition, we can also see that Buridan also admits two further subtypes of each: one broadly conceptual in nature, the other nonconceptual in nature. Insofar as subject-reflexive and state-reflexive cognition are conceptual in nature, they are the result of discursive processes; but insofar as they are non-conceptual, they are the result of an experiential mode of awareness. What is more, the latter-experientially-based-mode of reflexive awareness is prior to and appears to ground the formerconceptually-based - mode. Ultimately, therefore, knowledge of the soulincluding scientific knowledge-is grounded in what looks to be a kind of primitive, experiential awareness of one's own intellect and intellective functions.

To this point, I've not said anything particularly substantive regarding what Buridan's notion of subject and state-reflexive "experience" amounts to

\footnotetext{
${ }^{22}$ I take it that this mode of access to our states is, in fact, more widespread than the secondorder, discursively-based mode of state reflexive awareness on which PA focuses and which Buridan himself would no doubt have also endorsed.

${ }^{23}$ This is my own terminology, not Buridan's. As noted above, see note 15 , the notion of reflexivity has a fairly narrow, technical meaning for Buridan. When he speaks of reflexive cognition he has in mind a specific kind of discursive or reflective form of self-awareness. I'm using the term 'reflexive' much more broadly to refer to any kind of self-directedness.
} 
beyond noting that it is not a matter of one's possessing a discursively derived concept of one's intellect or intellective states. Can anything further be said about the nature of this mode of self-knowledge? Given that Buridan himself says nothing more than what we find in the passages quoted above, any such characterization must necessarily be speculative in nature. That said, I suggest that Buridan's talk of a subject "experiencing" her psychological states might be usefully compared to our own notion of consciousness or phenomenality. Read in this way, Buridan's claim that we experience our intellective states can be understood as a claim to the effect that such states have a kind of phenomenology-there is (as we are wont to say) something it is like for us to have or to occupy such states.

While speculative, this reading provides a natural interpretation of Buridan's views about the role such experience plays in the formation of our subjectand state-reflexive concepts. On Buridan's account, our possession of a generic concept of intellect presupposes (for its acquisition) a kind of preconceptual, pre-reflective awareness of ourselves as occupying certain intellective states or engaging in certain types of rational activity. In fact, we arrive at a concept of the intellect precisely as the result of introspective reflection on such experiences. Interpreting Buridan's notion of statereflexive experience in terms of phenomenal consciousness makes sense of such claims. After all, it is plausible to suppose that if our intellective states have some sort of basic phenomenality, their occurrence would yield a minimal form of self-awareness. They would, in other words, be something we experience ourselves as having when we have them. And this is precisely what Buridan himself seems to claim.

\section{Conclusion}

Admittedly, given the paucity of attention Buridan gives to the question of subject-reflexive knowledge, and that he gives no attention at all to the question of state-reflexive cognition, the evidence in favor of my reading of his notion of experience is far from decisive. In conclusion, I propose to situate Buridan's discussion vis-à-vis other late medieval treatments of selfreflexive knowledge. By calling attention to some of the ways in which his account resembles the accounts found in other medieval thinkers I hope to lend some plausibility to the interpretation I've been advancing. ${ }^{24}$

\footnotetext{
${ }^{24}$ I've considered later medieval accounts of self-knowledge at length elsewhere. See Brower-Toland (2012; 2013; Forthcoming).
} 
One of the hallmark features of a number of later medieval discussions of self-knowledge is the marking of a distinction between two types of subjectreflexive knowledge: one that is conceptual or thought-like in nature, the other characterized as being experiential in character. ${ }^{25}$ Whereas the conceptual form of subject-reflexive cognition yields knowledge of the nature of the intellective or rational soul in general; the latter is frequently construed as a type of pre-reflective access to one's own soul. What is more, this 'experiential' mode of subject-reflexive knowledge is typically characterized as being a constitutive feature of an experiential mode of state-reflexive awareness. $^{26}$ In light of what we've seen of Buridan's account, the idea

${ }^{25}$ Aquinas puts the distinction this way:

"...it should be noted that each person can have a twofold cognition of the soul as Augustine says in Book IX of De Trinitate. [1] One of these is a cognition by which the soul of each person cognizes itself only with respect to that which is proper to it. [2] The other is that by which the soul is cognized in terms of what it shares in common with all souls. This latter cognition, which applies generally to all souls, is that by which the nature of the soul is cognized. However, the cognition which each person has of own his soul insofar as it is his own, this is cognition of the soul insofar as it exists in this very individual. It is through this cognition [viz., type 1] that one cognizes whether the soul exists as when someone perceives (percipit) that he has a soul. Through the other type of cognition [viz., type 2], however, one knows both the soul's essence and its proper accidents." (DEVER 10.8c.)

Again, a similar distinction can be found in Peter Olivi:

It should be recognized that the soul knows itself in two ways. The first (1a) is by way of an experiential perception - similar in a way [to knowing something by] touch. In this way, the soul senses that it exists, lives, thinks, wills, sees, hears, and moves the bodyand so on concerning other of its acts of which it knows and senses itself to be the principle and subject. And this inasmuch as there is no object and no act that it can actually know or consider without its thereupon knowing and sensing itself to be the subject (suppositum) of act by which it knows and considers. ... Nevertheless, because the essential characteristics and properties of the soul are not sufficiently clear to everyone, they have to be studied and distinguished. Thus, although the mind senses and feels itself immediately through itself, it does not, nevertheless, know its nature by a genera and differentia distinguished from the genera and differentia of everything else. ... The second way (1b) of knowing is via discursive reasoning. Through this reasoning it investigates the genus and differentia, which it does not know by means of the first mode [of self-knowledge]. ... [In this reasoning process] it begins first from those things that it grasps and holds from itself through the first mode of knowing [- which things it grasps] as primary, infallible, and indubitable principles. For example, that it is a living thing, and that it is the principle and subject of all the aforementioned acts. (II Sent. 76, 146-7).

${ }^{26}$ See, for example, Aquinas's claim that the soul is cognized through its acts (DEVER 10.8c). Similarly, in his Impugnatio quorundam articulorum Arnalidi Galliardi articulus 19, 
should sound familiar enough: the intellective soul is experientially aware of itself via its awareness of itself as occupying its occurrent intellective states and activities. In other words, our subject-reflexive awareness is a function of experiencing oneself as the subject of ones own occurrent intellective states. It is not uncommon, therefore, to find medieval thinkers advocating the idea that there is a type of state-reflexive awareness that entails or is partly constituted by subject-reflexive awareness - namely, awareness of oneself as the subject of one's various occurrent states and operations.

This, I argue, is the mode of subject- and state-reflexive awareness that Buridan ascribes to his "vetula". The woman, in virtue of her subjective experience, is aware of herself as the subject of her various intellective states and operations. It's worth noting, moreover, that, like Buridan, other medieval thinkers often characterize the type of state-reflexive awareness as non-conceptual, and non-discursive in nature. ${ }^{27}$ Again, it is not a-typical to find such thinkers speaking of this mode of state-reflexive awareness in just the way Buridan himself does_-viz. in terms of "experience." ${ }^{28}$ Among such

Olivi claims "I never apprehend my acts (for example, acts of seeing, speaking, and so on) except by apprehending myself seeing, hearing, cognizing, and so on. And it would seem this apprehension presupposes I I $\mathrm{n}$ the natural order an apprehension of the subject itself (ipsius suppositum).... For we apprehend our acts only as being predicated or attributed to us. Indeed, when, by a certain internal sense, we apprehend our acts, we distinguish experientially (as it were) between the acts themselves on the one hand, and the substance on which these acts depend and in which they exist on the other." This text is edited by Sylvain Piron in Piron (2006).

27 They do this in different ways: some use metaphors involving sensory modes of awareness or terminology suggestive of an analog to such modes of awareness. See, for example, the passage from Olivi cited at n. 25 above where he characterizes this notion of self-awareness as "an experiential perception-similar in a way [to knowing something by] touch." Aquinas habitually uses the verb 'percipere' to characterize this mode of awareness - a very he seems to reserve largely for this particular type of cognition. See the passages quoted at nn. 25 and 26 above. Others indicate the non-cognitive nature of such self-awareness by insisting it is an experience that even characterizes states that are noncognitive in nature E.g., Walter Chatton's contention that such experiential awareness attends a conative state (even where such state is unaccompanied by any cognitive awareness): "It is the case, therefore, that if anyone has a proximate act of loving without any cognition of that proximate act, nevertheless, one will experience that act of loving, without any cognition of it. I confirm this in the second place since that which is experienced, namely the act of loving or thinking, does not exist except as an act received [in the mind]. But from the fact that the mind receives that act one is not entitled (contingit) to conclude that that act is its own object. Therefore, etc." (Collatio et Prologus, Prol. Q.1, a.1, 26-27)

${ }^{28}$ Thus Aquinas says: "each person experiences (experitur) in himself that he has a soul and that the acts of the soul are occurring in him" (DEVER 10.8 sc 8). Cf. Chatton's talk of "the 
authors, moreover, it is frequently held that this most primitive form of selfawareness provides the basis for a more articulated, more fully developed knowledge regarding the nature of the intellective soul. What the foregoing considerations show is that the view I have here attributed to Buridan is by no means unprecedented in medieval discussions of self-knowledge. That Buridan might be aware of or even presupposing such a view in his account the source of our knowledge of the intellect, and of our science of the soul in general is, I think, not implausible. ${ }^{29}$

experience by which [the soul] experiences something as an act." (Collatio et Prologus. Prol. Q.2, a.5, 120-1).

${ }^{29}$ I have argued elsewhere, that this late-medieval notion of state- and subject-reflexive selfawareness is the medieval analogue to our own notion of phenomenal consciousness. As I cannot recapitulate such arguments here, I am content to leave this element of my interpretation of Buridan's account as a working-hypothesis. 